\title{
ANALISIS KESTABILAN MODEL MANGSA PEMANGSA DENGAN PEMANENAN AMBANG BATAS PADA POPULASI PEMANGSA
}

\author{
Yusrianto $^{1^{*}}$, Syamsuddin Toaha $^{1^{*}}$, Kasbawati $^{{ }^{*}}$
}

\begin{abstract}
This study examines the model of one prey and one predator who mutates each other. The predation function of predators is assumed to use the Holling type II response function. Assuming that the existence of intraspecific competition in predatory population and theshold harvesting for predatory population is carried out. In this model, an analysis of the actual conditions and stability of the interior balance point is carried out. Analysis of the interior stability balance points was carried out by linearization method and by taking into account the eigenvalues of the Jacobian matrix obtained. There are ten equilibrium points of engagement obtained on the model, one of which can be interpreted. This point is stated as asymptotically stable. Based on the results of analysis using several parameters, it is known that there is a time when harvesting the threshold must be stopped because it has not fulfill the specified criteria for threshold.
\end{abstract}

Keyword : Prey-predator model threshold harvesting, equibrium point

\begin{abstract}
Abstrak
Penelitian ini mengkaji model satu mangsa dan satu pemangsa yang saling berkompetisi. Fungsi predasi dari pemangsa diasumsikan menggunakan fungs1 respon Holling tipe II. Dengan asumsi bahwa adanya kompetisi intraspesifik pada popuasi pemangsa serta dilakukan pemanenan ambang batas pada popuasi pemangsa. Pada model tersebut dilakukan analisis tentang syarat kewujudan dan kestabilan titik keseimbangan interior. Analisis kestabilan titik keseimbangan interior dilakukan dengan metode linearisasi dan dengan memperhatikan nilai eigen dari matriks Jacobi yang diperoleh. Terdapat sepuluh titik kesetimbangan yang diperoleh pada model, satu diantaranya dapat dinterpretasikan. Titik tersebut dinyatakan stabil asimtotik. Berdasarkan hasil anasis menggunakan beberapa parameter, diketahui bahwa ada suatu waktu pemanenan ambang batas harus dihentikan karna sudah tidak memenuhi syarat kriteria ambang batas yang telah ditentukan.
\end{abstract}

Kata kunci : Model mangsa pemangsa, Pemanenan ambang batas, Titik kesetimbangan

\footnotetext{
*Program Studi Matemamatika, Fakultas MIPA, Universitas Hasnauddin

1yhoes18@gmail.com, ${ }^{2}$ syamsuddint@gmail.com, ${ }^{3}$ kasbawati@gmail.com
} 


\section{Yusrianto, Syamsuddin Toaha, Kasbawati}

\section{Pendahuluan}

Model pertumbuhan logistik merupakan model pengembangan dari model pertumbuhan eksponensial, dengan asumsi bahwa populasi tidak dapat bertumbuh tanpa batas karena pertumbuhan populasi di pengaruhi oleh kepadatan populasi dan daya dukung lingkungan yang sifatnya terbatas,[5].

Pemodelan matematika pada bidang ekologi sangat menarik untuk dikaji mengingat banyaknya faktor-faktor yang mempengaruhi pertumbuhan dan kehidupan populasi mahluk hidup. Proses dinamika kehidupan makhluk hidup (organisme) dapat dimodelkan secara matematis dengan menggunakan persamaan differensial yang melibatkan waktu yang kontinu atau waktu yang diskrit. Salah satu model matematika yang digunakan dalam menjelaskan fenomena alam tersebut adalah model populasi mangsa-pemangsa,[1].

Model matematika dapat digunakan untuk menjelaskan prilaku fenomena alam yang terjadi, memprediksi prilaku sistem untuk suatu jangka waktu tertentu, dan dapat juga digunakan untuk mengambil suatu kebijakan,[2].

Kompetisi antar pemangsa dan faktor pemanenan pada populasi sangatlah penting dalam disiplin ilmu ekologi. Banyak peneliti yang dapat mengembangkan hal-hal menarik dari perilaku dinamika dalam populasi ekosistem. Dengan memadukan dua aspek di atas yaitu aspek kompetisi antar pemangsa dan pemanenan, maka dinamika populasi dapat dinyatakan dalam suatu model. Selain kompetisi antar pemangsa (kompetisi interspesifik) aspek menarik lainnya adalah kompetisi antar spesies dalam satu populasi (kompetisi intraspesifik),[3] mengkaji model tiga populasi dalam rantai makanan dengan kompetisi intraspesifik.

Selain kompetisi antar populasi pemanenan juga sangat berpengaruh dalam pemodelan dinamika populasi. Salah astunya yaitu pemanenan ambang batas. Dengan membiarkan predator tumbuh sampai populasi menyentuh ambang dan kemudian memanen hingga melewati ambang ambang batas ,[4]. Penelitian lainnya tentang pemanenan ambang batas dapat dilihat dalam, [4,6,7].

Perbedaan yang mendasar pada penelitian ini dengan beberapa penelitian sebelumnya adalah penelitian ini mengkaji model satu mangsa-satu pemangsa yang melibatkan kompetisi intraspesifik serta pemanenan ambang batas pada populasi pemangsa

\section{Pengembangan Model}

Model mangsa pemangsa yang dikembangkan dalam penelitian ini yaitu model mangsa pemangsa oleh Rozenzweig-MacArthur [4] :

$$
\begin{aligned}
& \frac{d x}{d t}=r x\left(1-\frac{x}{K}\right)-y\left(\frac{s x}{1+s \alpha x}\right) \\
& \frac{d y}{d t}=e y\left(\frac{s x}{1+s \alpha x}\right)-p y
\end{aligned}
$$

Kemudian dikembangkan oleh Benjamin Lenard dan Jorge Rebaza [4]dengan menambahkan fungsi pemanenan ambang batas yaitu :

$$
\begin{aligned}
& \dot{x}=a {\left[x(1-x)-\frac{x y}{1+b x}\right] } \\
& \dot{y}=y\left(\frac{b x}{1+b x}-d\right)-H(y)
\end{aligned}
$$

Dengan kriteria ambang batas : 


\section{Yusrianto, Syamsuddin Toaha, Kasbawati}

$$
H(y)=\left\{\begin{array}{cc}
0, & \text { Jika } y<T \\
h \frac{(y-T)}{h+(y-T)} & \text { Jika } y>T
\end{array}\right.
$$

Berdasarkan kedua model tersebut, dilakukan pengembangan model mangsa pemagsa dengan pemanenan ambang batas pada populasi pemangsa serta diasumsikan terjadinya kompetisi intraspesifik pada populasi pemangsa Sehingga model mangsa pemangsa yang dikembangkan dalam penelitian ini yaitu :

$$
\begin{aligned}
& \frac{d x}{d t}=r x\left(1-\frac{x}{K}\right)-y\left(\frac{s x}{1+s \alpha x}\right) \\
& \frac{d y}{d t}=e y\left(\frac{s x}{1+s \alpha x}\right)-p y-c y^{2} .
\end{aligned}
$$

Normalisasi model mangsa pemangsa dengan pemanenan ambang batas pada populasi pemangsa :

$$
\begin{aligned}
& \frac{d x}{d t}=x(1-x)-a\left(\frac{x y}{1+b x}\right) \\
& \frac{d y}{d t}=u\left(\frac{x y}{1+b x}\right)-v y-w y^{2},
\end{aligned}
$$

dimana $a=\frac{s k}{r e}, b=s \alpha K, u=\frac{s k e}{r}, v=\frac{p}{r}$ dan $w=\frac{c k}{r e}$.

Selanjutya dengan menambahkan fungsi pemanenan ambang batas pada populasi pemangsa sehingga model mangsa pemangsa yang diperoleh yaitu :

$$
\begin{aligned}
\frac{d x}{d t} & =x(1-x)-a\left(\frac{x y}{1+b x}\right) \\
\frac{d y}{d t} & =u\left(\frac{x}{1+b x}\right)-v y-w y^{2}-H(y),
\end{aligned}
$$

dimana $H(y)$ adalah kriteria ambang batas yaitu :

$$
H(y)=\left\{\begin{array}{cc}
0, & \text { Jika } y<y_{c} \\
h \frac{(y-T)}{h+(y-T)} & \text { Jika } y>y_{c}
\end{array}\right.
$$

\section{Analisis Kestbilan Titik Kesetimbangan}

\section{a. Analisis titik kesetimbangan}

Titik kesetimbangan non negatif dari model (2.5) dengan $H(y)=h \frac{\left(y-y_{c}\right)}{h+\left(y-y_{c}\right)}$, dimana $y>y_{c}$ adalah sebagai berikut.

Pandang model mangsa peangsa berikut : 


\section{Yusrianto, Syamsuddin Toaha, Kasbawati}

$$
\begin{aligned}
& \frac{d x}{d t}=x(1-x)-a\left(\frac{x y}{1+b x}\right) \\
& \frac{d y}{d t}=u\left(\frac{x}{1+b x}\right)-v y-w y^{2}-h \frac{\left(y-y_{c}\right)}{h+\left(y-y_{c}\right)},
\end{aligned}
$$

misalkan $\frac{d x}{d t}=f(x, y)$ dan $\frac{d y}{d t}=g(x, y)$, diperoleh

$$
\begin{aligned}
& f(x, y)=x(1-x)-a\left(\frac{x y}{1+b x}\right) \\
& g(x, y)=u\left(\frac{x}{1+b x}\right)-v y-w y^{2}-h \frac{\left(y-y_{c}\right)}{h+\left(y-y_{c}\right)},
\end{aligned}
$$

dengan menyamakan dengan nol untuk masing-masing persamaan (2.5) diperoleh

$$
\begin{aligned}
& f(x, y)=x(1-x)-a\left(\frac{x y}{1+b x}\right)=0 \\
& g(x, y)=u\left(\frac{x}{1+b x}\right)-v y-w y^{2}-h \frac{\left(y-y_{c}\right)}{h+\left(y-y_{c}\right)}=0
\end{aligned}
$$

untuk $f(x, y)=0$ diperoleh

$$
y^{*}=\frac{-b x^{3}+(b-1) x^{2}+x}{a x},
$$

untuk $g(x, y)=0$ dan $y=\frac{-b x^{3}+(b-1) x^{2}+x}{a x}$ diperoleh

$\left(-b^{4} w\right) x^{10}+\left(b^{4} w\right) x^{9}+\left(a b^{3} v-y_{c} a b^{3} w+a b^{3} h w+2 b^{2} w\right) x^{8}+\left(-2 a b^{3} v+3 a b^{2} v-a b^{2} h w+\right.$ $\left.2 b^{4} w+2 b^{3} w-2 b^{2} w\right) x^{7}+\left(-a^{2} b^{2} h+a^{2} b u+a b^{3} v-6 a b^{2} v+3 a b v-w+y_{c} a^{2} b^{2} v+t a b w-\right.$ $\left.a^{2} b^{2} h v-a b h w-2 b^{4} w+2 b^{2} w\right) x^{6}+\left(-y_{c} a w+a^{2} b^{2} h-2 a^{2} b h-a^{2} b u+3 a b^{2} v-6 a b v+\right.$ $a h w+w-y_{c} a^{2} b^{2} v+2 y_{c} a b^{3} w+2 y_{c} a^{2} b v+2 y_{c} a b^{2} w+a^{2} b^{2} h v-2 a^{2} b h v-2 a b^{3} h w-$ $\left.2 a b^{2} h w+a^{2} u+a v-2 b^{3} w-4 b^{2} w-2 b w\right) x^{5}+\left(-a^{3} h u+y_{c} a^{3} u+y_{c} a^{2} v+2 a^{2} b h-a^{2} h v+\right.$ $\left.3 a b v-y_{c} a^{3} b h-2 y_{c} a^{2} b v+2 a^{2} b h v-a^{2} h-a^{2} u-2 a v-b^{4} w-2 b^{3} w+b^{2} w-2 w\right) x^{4}+$ $\left(-y_{c} a^{3} h-y_{c} a^{2} v-2 y_{c} a w+a^{2} h v+2 a h w+2 w-2 y_{c} a b w+2 a b w h+a^{2} h+a v+b^{4} w-\right.$ $\left.3 b^{2} w\right) x^{3}+\left(-w+a b h w-y_{c} a b^{3} w-y_{c} a b^{2} w-y_{c} a b w+a b^{3} h w+2 a b^{2} h w+2 b^{3} w+\right.$ $\left.3 b^{2} w\right) x^{2}+\left(-y_{c} a w+a h w+w+a b^{2} h w+2 a b h w-y_{c} a b^{2} w-2 y_{c} a b w+b^{2} w x+2 b w\right) x=0$.

Persamaan (3.5) yang diperoleh merupakan persamaan polinom berderajat 10 yang sulit diselesaikan dengan cara analitik. Dengan alasan tersebut maka pencarian titik kesetimbangan dilakukan dengan menggunakan simulasi pada aplikasi Maple. Maka dari itu hanya akan dilakukan pendekatan pemberian nilai parameter untuk mencari titik kestimbangan $(\mathrm{x}, \mathrm{y})$ yang stabil.

Nilai parameter yang digunakan dalam simulasi yaitu $a=0.5, b=5, d=0.2, h=4, f=$ $0.3, g=5$ dan $y_{c}=0,2$

Pada bagian simulasi numerik ini,simulasi dilakukan hanya pada kestabilan titik kesetimbangan interior karena pada titik kesetimbangan itulah semua populasi eksis dan semua komponen (parameter) dalam model (2.5) dapat diinterpretasikan.

Titik kesetimbangan yang diperoleh untuk nilai $y_{c}(0,2)=(0.9635154325,0.4245035734)$ 


\section{Yusrianto, Syamsuddin Toaha, Kasbawati}

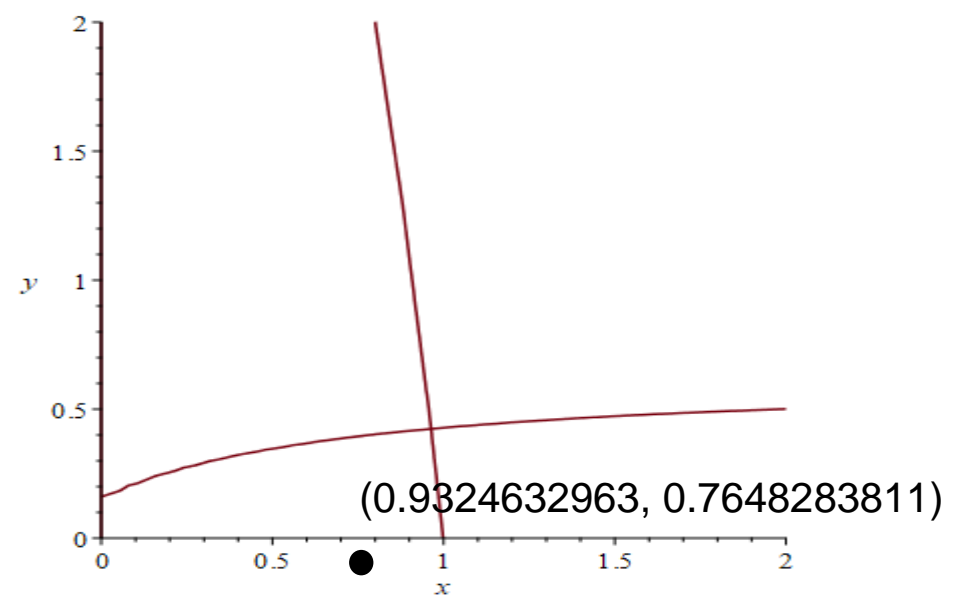

Gambar 3.1 Titik Kesetimabangan Populasi Mangsa dengan

Kriteria Ambang Batas $y_{c}=0,2$

\section{b. Analisis Kestabilan Titik Kesetimbangan}

Matriks Jacobi dari model (2.5) dengan $H(y)=h \frac{\left(y-y_{c}\right)}{h+\left(y-y_{c}\right)}$, dimana $y>y_{c}$ adalah sebagai berikut.

dengan

$$
J=\left[\begin{array}{ll}
J_{11} & J_{12} \\
J_{21} & J_{22}
\end{array}\right]
$$

$$
\begin{aligned}
& J_{11}=\frac{d}{d x} f(x, y)=\frac{d}{d x}\left(x(1-x)-a\left(\frac{x y}{1+b x}\right)\right)=\frac{d}{d x}\left(x-x^{2}-a\left(\frac{x y}{1+b x}\right)\right) \\
&= 1-2 x-a \frac{y(1+b x)-b x y}{(1+b x)^{2}}=1-2 x-\frac{a y}{(1+b x)^{2}}, \\
& J_{12}=\frac{d}{d y} f(x, y)=\frac{d}{d y}\left(x(1-x)-a\left(\frac{x y}{1+b x}\right)\right)=\frac{d}{d y}\left(x-x^{2}-a\left(\frac{x y}{1+b x}\right)\right)=-\frac{a x}{1+b x^{\prime}} \\
& J_{21}=\frac{d}{d x} g(x, y)=\frac{d}{d x}\left(u\left(\frac{x}{1+b x}\right)-v y-w y^{2}-h \frac{\left(y-y_{c}\right)}{h+\left(y-y_{c}\right)}\right)=\frac{u}{(1+b x)^{2}} \\
& J_{22}=\frac{d}{d y} g(x, y)=\frac{d}{d y}\left(u\left(\frac{x}{1+b x}\right)-v y-w y^{2}-h \frac{\left(y-y_{c}\right)}{h+\left(y-y_{c}\right)}\right)=-v-2 w y-\frac{h^{2}}{\left(h+\left(y-y_{c}\right)\right)^{2}} \\
& y_{c}=\left(x_{*}, y_{*}\right)
\end{aligned}
$$

Sehingga matriks Jacobian yang bersesuaian dengan sistem (2.5) adalah sebagai berikut.

$$
J=\left[\begin{array}{cc}
1-2 x-\frac{a y}{(1+b x)^{2}} & \frac{u}{(1+b x)^{2}} \\
-\frac{a x}{1+b x} & -v-2 w y-\frac{h^{2}}{\left(h+\left(y-y_{c}\right)\right)^{2}}
\end{array}\right]
$$

Dengan mensusbtitusi $y_{c}$ pada (3.7) diperoleh 


\section{Yusrianto, Syamsuddin Toaha, Kasbawati}

$$
J\left(y_{c}\right)=\left[\begin{array}{ll}
J_{11}^{4} & J_{12}^{4} \\
J_{21}^{4} & J_{22}^{4}
\end{array}\right]
$$

dengan

$$
\begin{aligned}
& J_{11}=1-2 x_{*}-\frac{a y_{*}}{\left(1+b x_{*}\right)^{2}}, \\
& J_{12}=-\frac{a x_{*}}{1+b x_{*}}, \\
& J_{21}=\frac{u}{\left(1+b x_{*}\right)^{2}} \\
& J_{22}=-v-2 w y_{*}-\frac{h^{2}}{\left(h+\left(y_{*}-y_{c}\right)\right)^{2}},
\end{aligned}
$$

Dari matriks jacobi $J\left(T_{4}\right)$ diperoleh persamaan karakteristik sebagai berikut

$$
\lambda^{2}+A_{1} \lambda+A_{2}=0
$$

dimana

$$
\begin{aligned}
& A_{1}=-\left(J_{11}+J_{22}\right) \\
& A_{1}=-\left(\left(1-2 x_{*}-\frac{a y_{*}}{\left(1+b x_{*}\right)^{2}}\right)+-v-2 w y_{*}-\frac{h^{2}}{\left(h+\left(y_{*}-T\right)\right)^{2}}\right) \\
& A_{2}=\left(J_{11} J_{22}-J_{21} J_{12}\right) \\
& A_{2}=\left(\left(1-2 x_{*}-\frac{a y_{*}}{\left(1+b x_{*}\right)^{2}}\right)\left(-v-2 w y_{*}-\frac{h^{2}}{\left(h+\left(y_{*}-y_{c}\right)\right)^{2}}\right)-\left(\frac{u}{\left(1+b x_{*}\right)^{2}}\right)\left(\frac{a x_{*}}{1+b x_{*}}\right) .\right.
\end{aligned}
$$

Untuk menjamin kestabilan $y_{c}$ harus memenuhi kriteria Routh-Hurwitz, yakni

$A_{1}>0$ dan $A_{2}>0$

a. $A_{1}>0$

$$
-\left(J_{11}+J_{22}\right)>0
$$

b. $A_{2}>0$

$\left(J_{11} J_{22}-J_{21} J_{12}\right)>0$

Jadi, titik kesetimbangan $y_{c}$ stabil asimtotik jika memenuhi kondisi

$-\left(J_{11}+J_{22}\right)>0,\left(J_{11} J_{22}-J_{21} J_{12}\right)>0$.

\section{Simulasi Numerik}

a. Parameter $y_{c}=\mathbf{0 , 2}$

Nilai parameter yang digunakan dalam simulasi yaitu $a=0,5, b=5, d=0,2, h=4, y_{c}=$ $0,2, f=0,3, g=5$

Pada bagian simulasi numerik ini,simulasi dilakukan hanya padakestabilan titik kesetimbangan interior karena pada titik kesetimbangan itulah semua populasi eksis dan semua komponen (parameter) dalam model (2.5) dapat diinterpretasikan.

Titik kesetimbangan yang diperoleh yaitu $y_{c}=(0,9635154325,0,4245035734)$.

Matriks Jacobi dari $y_{c}$ adalah 


\section{Yusrianto, Syamsuddin Toaha, Kasbawati}

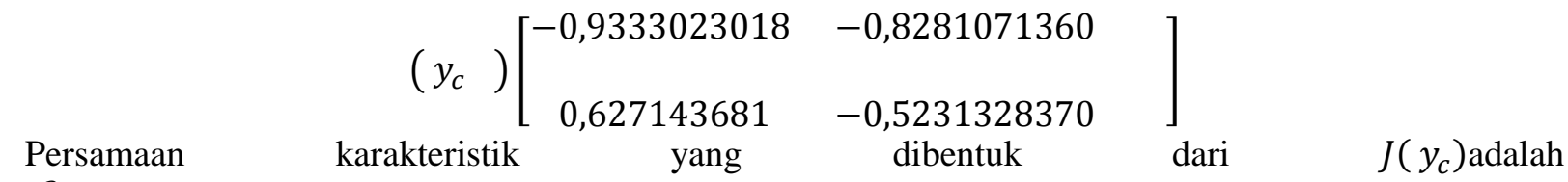
$\lambda^{2}+1,45643513 \lambda+0,4934345025$.

Nilai eigen yang diperoleh adalah $\lambda_{1}=-0,920223626305103, \quad \lambda_{2}=$ $-0.536211512494897$.

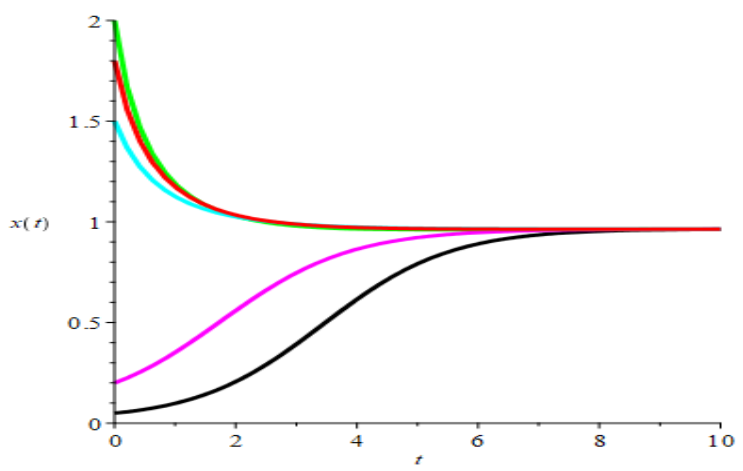

Gambar 4.1 Kurva Trayektori Populasi Mangsa dengan Kriteria Ambang Batas

$$
y_{c}=0,2
$$

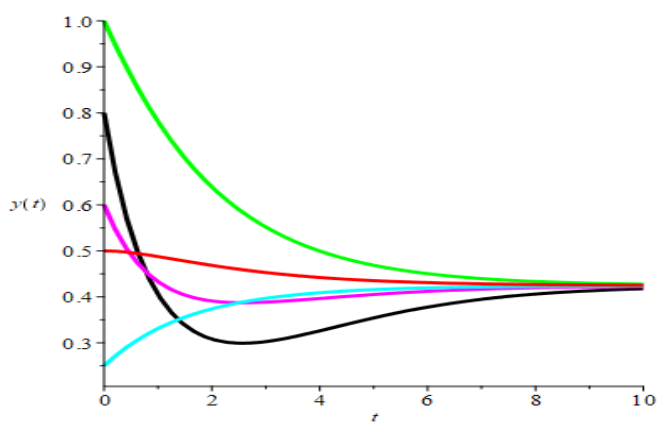

Gambar 4.2 Kurva Trayektori Populasi Pemangsa dengan Kriteria Ambang Batas $y_{c}=0,2$

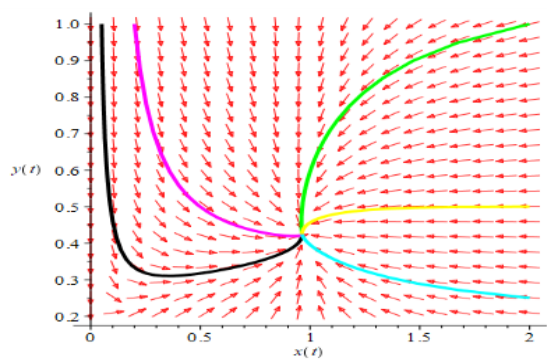

Gambar 4.3 Kurva Trayektori Model Populasi Mangsa Pemangsa dengan Kriteria Ambang Batas $y_{c}=0.2$

Dari gambar 4.1, dan gambar 4.2 menunjukkan kurva trayektori poulasi mangsa dan pemangsa untuk nilai parameter $y_{c}=0,2$. sementara gambar 4.3 menunjuka arah pergerakan populasi mangsa dan pemangsa menuju titik kesetimbangan untuk parameter $y_{c}=0,2$. 


\section{Yusrianto, Syamsuddin Toaha, Kasbawati}

\section{b. Parameter $y_{c}=2,1$}

Nilai parameter yang digunakan dalam simulasi yaitu $a=0,5, b=5, d=022, h=4, T=$ $211, f=0,3, g=5$

Pada bagian simulasi numerik ini,simulasi dilakukan hanya padakestabilan titik keseimbangan interior karena pada titik keseimbangan itulah semua populasi eksis dan semua komponen (parameter) dalam model (4.7) dapat diinterpretasikan.

Titik keseimbangan yang diperoleh yaitu $y_{c}=(0,8458311664,1,612345710)$.

Matriks Jacobi dari $y_{c}$ adalah

$$
\left(\begin{array}{l}
y_{c}
\end{array}\right)\left[\begin{array}{cc}
-0,7211448802 & -0,8087645440 \\
0,294825472 & -1,260363435
\end{array}\right]
$$

Persamaan karakteristik yang dibentuk dari $J\left(y_{c}\right)$ adalah

$\lambda^{2}+1,98150831 \lambda+0,9327490771$.

Nilai eigen yang diperoleh adalah $\lambda_{1}=-0,769745733285487, \lambda_{2}=-1,21176258191451$.

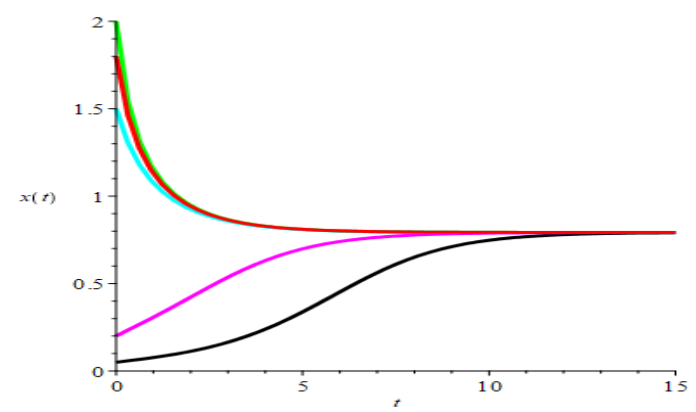

Gambar 4.4 Kurva Trayektori Populasi Mangsa dengan Kriteria Ambang Batas

$$
y_{c}=2,1
$$

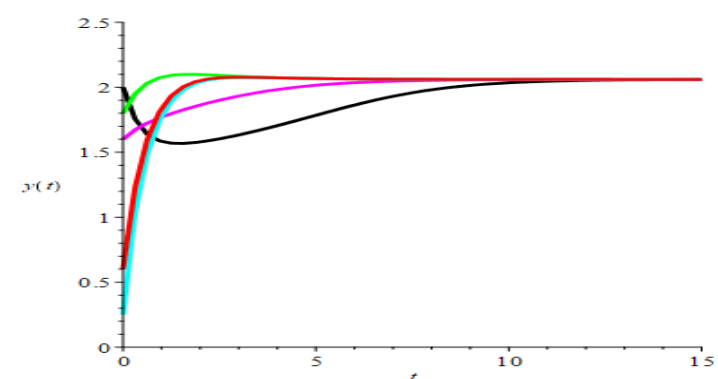

Gambar 4.5 Kurva Trayektori Populasi Pemangsa dengan Kriteria Ambang Batas $y_{c}=2,1$ 


\section{Yusrianto, Syamsuddin Toaha, Kasbawati}

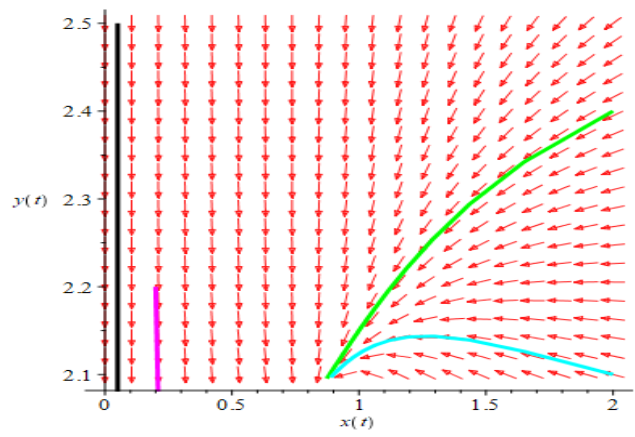

Gambar 4.6 Kurva Trayektori Model Populasi Mangsa Pemangsa dengan Kriteria Ambang

Batas $y_{c}=2,1$

Dari gambar 4.4, dan gambar 4.5 menunjukkan kurva trayektori poulasi mangsa dan pemangsa untuk nilai parameter $y_{c}=2,1$. sementara gambar 4.6 menunjuka arah pergerakan populasi pemangsa menuju titik kesetimbangan untuk parameter $y_{c}=2,1$. karena titik equilibrium berada dibawah ttik $y=1,5$ sehingga titik equilibrium pada saat $y_{c}=2,1$ tidak terlihat. Karena $y_{c}>y$ makapemanenan ambang batas pada $y_{c}=2,1$ harus dihentiakan pada titik $y=2,1$ sebab sudah tidak memenuhi syarat pemanenan ambang batas $H(y)$.

\section{Kesimpulan}

a. Model satu mangsa-satu pemangsa dengan pemanenan optimal pada pemangsa adalah sebagai berikut

$$
\begin{gathered}
\frac{d x}{d t}=x(1-x)-a\left(\frac{x y}{1+b x}\right) \\
\frac{d y}{d t}=u\left(\frac{x}{1+b x}\right)-v y-w y^{2}-H(y) \\
\text { dengan } H(y)=\left\{\begin{array}{cc}
0, & \text { Jika } y \leq y_{c} \\
h \frac{\left(y-y_{c}\right)}{h+\left(y-y_{c}\right)} & \text { Jika } y>y_{c}
\end{array}\right.
\end{gathered}
$$

b. Hasil simulasi dengan mengambil nilai parameter $y_{c}$ yang berbeda menunjukkan bahwa ada suatu kondisi yang menunjukkkan bahwa pemanenan ambang batas pada populasi pemangsa harus dihentikan karena sudah tidak memenuhi syarat $H(y)$ yaitu

$$
H(y)=\left\{\begin{array}{cc}
0, & \text { Jika } y \leq y_{c} \\
h \frac{\left(y-y_{c}\right)}{h+\left(y-y_{c}\right)} & \text { Jika } y>y_{c}
\end{array}\right.
$$

\section{Daftar pustaka}

[1] Saenz, R.A. dan Hethcote, H.W., 2006. Competing Species Models with an Infectious Disease, $J$. Math. Biosci. Eng. 3 (1):219-235 
Yusrianto, Syamsuddin Toaha, Kasbawati

[2] Toaha. S., 2013. Pemodelan Matematika Dalam Dinamika Populasi. Dua Satu Press: Makassar.

[3] Ali N., Haque M., Venturino E. dan Chakravarty S., 2017. Dynamics of a Three Species RatioDependent Food Chain Model with Intra-Specific Competition within The Top Predator. Computers in Biology and Medicine. 85: 63-74.

[4] Leard, B dan Rebaza, J., 2010. Analysis of Predator-Prey Models with Continuous Threshold Harvesting. Applied Mathematics and Computation. 217 : 5265-5278.

[5] Waluya, S.T., 2011. An Introduction to Differential Equations. Unnes Press: Semarang.

[6] Liu, Z. dan Tan, R., 2007. Impulsive Harvesting and Ttocking in a Monod-Haldane Functional Response Predator-Prey System. Chaos, Solitons and Fractals. 34: 454-464.

[7] Lv.Y, Yuan R.dan Pei Y., 2013. Dynamic in Two Nonsmooth Predator-Prey Models with Threshold Harvesting. Springer-Verlag. 